\title{
Development and Aging Behaviour of Solvent-Based Polychloroprene Rubber Nano-Adhesive Using Multiwall Carbon Nanotubes
}

\author{
Muhammad Awais, Muhammad Shahid*, Mohsin Saleem, Fariz Aneeq, Muhammad Shoaib Butt, \\ Malik Adeel Umer
}

School of Chemical and Materials Engineering, National University of Sciences \& Technology, Islamabad, Pakistan

Email: *mshahid@scme.nust.edu.pk

How to cite this paper: Awais, M., Shahid, M., Saleem, M., Aneeq, F., Butt, M.S. and Umer, M.A. (2020) Development and Aging Behaviour of Solvent-Based Polychloroprene Rubber Nano-Adhesive Using Multiwall Carbon Nanotubes. Journal of Materials Science and Chemical Engineering, 8, 31-44.

https://doi.org/10.4236/msce.2020.89004

Received: August 14, 2020

Accepted: September 25, 2020

Published: September 28, 2020

Copyright $\odot 2020$ by author(s) and Scientific Research Publishing Inc. This work is licensed under the Creative Commons Attribution International License (CC BY 4.0).

http://creativecommons.org/licenses/by/4.0/

\begin{abstract}
Polychloroprene (PC) based contact adhesives are widely used in various applications; however, there is a possibility to improve the properties of $\mathrm{PC}$ adhesive. Modifications of polymers can enhance the properties of the material, e.g. increase in thermal stability, compatibility, rigidity, physical response, flexibility and improve the polymer process ability. In the current study, improved formulation of solvent-based adhesive was developed, and the properties were further enhanced by the addition of nano-reinforcement of multiwall carbon nanotubes (MWCNTs). The addition of nano-reinforcement was optimized to obtain improvement in the bond strength and also to enhance its resistance at a high temperature $\left(\sim 100^{\circ} \mathrm{C}\right)$. This paper discusses the uniform dispersion of MWCNTs during the synthesis of polychloroprene solvent-based adhesive, thereby improving its structural properties. Incorporation of MWCNTs-solvent-based adhesives resulted in a 20\% - 35\% improvement in $180^{\circ}$ peel strength determined on flexible substrates such as canvas, leather. The reinforced based adhesive also exhibited improved thermal stability and weather resistance compared with unreinforced adhesive. The MWCNTssolvent-based contact adhesives is a potential candidate in an industrially relevant branch of adhesives commonly used in structural applications, e.g., footwear, plastic, leather, automobile, construction industries, etc.
\end{abstract}

\section{Keywords}

Nanocomposite, Polychloroprene, Adhesive, Peel Strength, Carbon

Nanotubes 


\section{Introduction}

The phenomenon of transferring loads from adherend to adhesive joint is known as adhesion [1]. Mechanical properties of polymer control the interfacial forces necessary for good adhesion. Sustaining sufficient stresses at the interface is the basis for high adhesion [2]. There is always intermolecular diffusion taking place between the surfaces joined together by contact adhesives. In any interfusion process, the organic liquid evaporates, thus forming a strong bond between the layers; the bonding starts to take place when two properly layered bonding surfaces are brought closer. Several major parameters play a pivotal role in the auto adhesion to take place. The polymer or binding material must have diffusive properties. Diffusive property of binding material depends on solvent and the polymer used. There are only selective polymers which exhibit excellent auto adhesion properties. Intimate and close contact of the substrate is compulsory for the highest diffusion. Elastic stress and rheology of composition affect the quality of bond strength. When the adhesive is coated correctly on the material and dried in a lap of time under ambient conditions, this time is called open time. Adhesive layer alters all the physical properties in the open time due to evaporation of the solvent, interfacing of polymers, the base of polymer changes and crystallization of binding polymers [3]. When the open time has been passed, auto adhesion or good adhesive properties of the surfaces can't be achieved.

\subsection{Properties of Contact Adhesive}

Contact adhesives are used because of their excellent mechanical properties, high strength, fast setting time, easy applicability and durability [4]. It can be used as solvent-based as well as water-based depending upon the type of application. In solvent-based technology, the solvent evaporates very quickly from the surface, and very high bond strength is observed, which increases with time [5]. Some of the properties which affect the strength and its performance are viscosity [6], storage life [7] [8], working life, tack time [9] [10], acid acceptance [11], surface free energy and wettability [12] [13], etc. Resins are added in contact adhesives formulations to modify viscosity, tack time and strength of adhesive. Resins act as tackifying agent in adhesives. They are available in various colors ranging from transparent to brown. They are soluble in aliphatic, aromatic and organic compounds.

Phenolic resins are widely used in adhesive formulation; however, many alternatives are now being developed. Modified resins are also used in the adhesive formulation. Tack time is decreased when the resin amount is increased from 80 $\mathrm{phr}$ (parts per hundred) to $85 \mathrm{phr}$ [9]. Solvent-based adhesives are commonly used in packing, automotive, construction, footwear and furniture industries. However, due to safety and environmental issues, chlorinated solvents are banned. Solvents are selected depending on the drying rate and retention time [14]. Contact adhesives have excellent thermal and electric insulation. They can 
withstand the temperature of about $130^{\circ} \mathrm{C}$. Uniform stress distribution and lightweight structures can be built by using contact adhesives [3] [15]. Water-based contact adhesives are gradually replacing solvent-based adhesives, however, they require excessive time to dry, which restrict their applicability [16] [17].

Adhesive bonding is a result of various physio-chemical interactions taking place between materials to be joined and the adhesive. So, adhesive bonding needs some understanding of these processes taking place on the surface of materials [17]. Various theories describing adhesion mechanisms are mechanical interlocking, electrostatic adhesion, diffusion, and surface reaction. However, it is challenging to associate adhesive bonding with a particular theory. Adhesive bonding is the result of the combination of these mechanisms, but the role of each mechanism changes for carious adhesive systems [18]. An essential factor in adhesive bonding is the scale at which adhesive and adherend interaction takes place. Table 1 shows a rough range of action of a particular mechanism [8]. Mechanisms of various theories have been explained at numerous references, e.g., a mechanical method [19], ways to improve mechanical bonding [20]; electrostatic theory [21]; weak boundary layer [22]; diffusion theory [23]; adsorption theory [24] etc.

\subsection{Polychloroprene Rubber-Based Adhesives}

One of the most critical applications in which Neoprene ${ }^{\circledR}$ adhesive finds its place is in shoe industry, for both permanent and temporary sole bonding. However, the early neoprene cement had two problems: 1) discoloration when stored in steel drums and 2) decrease in viscosity when stored for a more extended period [25]. The discoloration was due to the formation of hydrochloric acid formed by oxidation of Neoprene on ageing. Magnesium oxide and zinc oxide were added in small quantity to prevent the discoloration. However, their addition decreased the viscosity stability of adhesive. Addition of phenolic resin increases the threshold value of the cohesive strength of Neoprene while the former decreased its strength at high temperatures [26]. The essential requirement for the excellent bond is 1) Proper choice of adhesive; 2) Good joint design; 3) Surface preparation; 4) Wettability; 5) Proper bonding process. According to a few reports, surface treatment is directly proportional to life and service expectancy of any adhesive joint [17]. The surface treatment is required to remove any layer of containment

Table 1. Theories of adhesion [8].

\begin{tabular}{ccc}
\hline Traditional & Recent & Scale of Action \\
\hline Mechanical Interlocking & Mechanical Interlocking & Microscopic \\
Electrostatic & Electrostatic & Macroscopic \\
Diffusion & Diffusion & Molecular \\
Adsorption/surface reaction & Wettability & Molecular \\
& Chemical Bonding & Atomic \\
& Weak Boundary Layer & Molecular \\
\hline
\end{tabular}


like dirt, grease or oil, which appears to be the surface of substrates [27]. There are multiple ways to clean these surfaces for better wettability, some surface preparation methods: Solvent Cleaning [28]; Chemical treatment [29]; Mechanical treatment [5]; Chemical etching [30]; Plasma treatment [31]; Corona treatment [32]; Flame treatment [10] etc. A large-scale variety of rubber-based PCA (Polychloroprene adhesives) is available based on cost and end-use. Several components and the mixture of solvents are used to formulate PCA [33]. End-use of adhesive application having various rate of crystallization of neoprene rubber is also available, which includes neoprene $\mathrm{AD}$, neoprene $\mathrm{AC}$, neoprene blends of polychloroprene and its co-polymers are also used to attain desired properties of adhesive [34]. Polyphenols, hexamethylenetetramines and condensation products of amines with aldehydes, di-phenyl aniline and polyisocyanates can be used for self-curing of adhesives. Hexamethylenetetramine and paraformaldehyde are used as aldehydes. To increase the vulcanization, process promoters can be added [35]. Various functional groups are introduced to increase the strength of multilayer resin products of adhesives. Functional groups are in the form of additives to boost the adhesion strength to resins. Many researchers prefer phenol resins or resins based on cyclopentadiene to improve the gluing properties of the polychloroprene adhesives [34]. The ageing particularizations of contact adhesives can be affected using resins. The ageing can be increased and decreased using the resins. The resins must be blended with the antioxidants to get the best mechanical properties of the adhesives.

\subsection{Nanoscale Reinforcement in Adhesives}

The adhesion properties can be improved by introducing a minute amount of nanoparticles like multi-walled carbon nanotubes, Nano clay and graphene [36]. A successful dispersion of Nano-fillers (carbon nanotubes, nano-clay, nanofibers) into a matrix of a polymer (thermosetting or thermoplastic) plays an important role. A nanocomposite is a unique combination of improved properties like physical, chemical and mechanical properties. The Nano-fillers have exceptionality due to their size and large surface area over traditional fillers [37].

In this research, MWCNTs was added in solvent-based adhesives to increase the mechanical properties of adhesion in different ageing conditions from ambient to high temperature. Peel strength of unreinforced and reinforced based adhesives was investigated and compared it with commercially available adhesives.

\section{Experimental Procedure}

Materials used in the formulation of adhesive were: Polychloroprene rubber (Mw. 120,000); Phenolic Resin (Mw. 700); Solvents such as Toluene, Ethyl acetate, Naphtha, DMF (Dimethylformamide); Magnesium oxide (MgO)/Zinc Oxide ( $\mathrm{ZnO})$; Antioxidant; Nanofillers as Multi-walled carbon nanotubes (MWCNTs; diameter $10-30 \mathrm{~nm}$ ). All materials were of commercial-grade expect DMF (role) (Sigma Aldrich, 99\%). Commercial grade functionalized MWCNTs were 
procured from Sun Nanotech ${ }^{\circledR}$ with a purity of $90 \%$. Table 2 displays the quantities of ingredients used for polychloroprene solvent-base adhesive; the amounts were optimized after multiple iterations.

Direct dissolving technique was used to carry out the experimentation in the laboratory. After successful tests at a smaller scale, the production was scaled up using an indigenously developed impeller mixing machine with controlled temperature and along with variable low $\mathrm{rpm}$. All ingredients were added one-by-one in a mechanical mixer, and the temperature was gradually increased to $60^{\circ} \mathrm{C}$. The optimized adhesive was given the name "PA-30". Dispersion of MWCNTs in DMF was performed using ultrasonic bath [38]. The dispersed solution was added to already fabricate PCA (Polychloroprene adhesive) during a continuous mechanical mixing. Mixing of adhesive is done until the pale yellow colour of the adhesive changes into greenish colour and developing a nanocomposite adhesive. The whole process took 3 to 4 hours. Schematic diagram of mixing is shown in Figure 1.

\section{Preparation of Samples for Mechanical Testing}

Two types of substrates 1) Canvas-to-Canvas and 2) Leather-to-Leather were used for peel testing as per ASTM standard D903 (2017). The adhesives were applied using a brush and a doctor blade and allowed to almost before joining together and gentle pressing using a roller. $180^{\circ}$ angle peel testing was performed as per ASTM standard D3330, using a UTM.

\section{Results and Discussion}

Figure 2 displays the effect of MWCNTs' concentration on peel strength of the Nano composite adhesive. There was a gradual increase in peel strength up to a certain amount of MWCNTs (0-1\%) followed by a stable rather a decreasing trend. The enhancement in strength was due to compatibility of the MWCNTs with the resin and the adhesive system. In both cases i.e. canvas-to-canvas and leather-to-leather substrates, maximum peel strength was obtained by incorporating $\approx 0.8 \%$ MWCNTs.

Table 2. The optimized formulation of solvent-based adhesive "PA-30".

\begin{tabular}{ccc}
\hline Sr. No & Chemicals & Parts per hundred \\
\hline CR & 100 \\
Resin & 55 \\
Antioxidant & 4 \\
Ethyl Acetate & 320 \\
Toluene & 180 \\
MgO & 3 \\
Naphtha & 220 \\
ZnO & 3
\end{tabular}




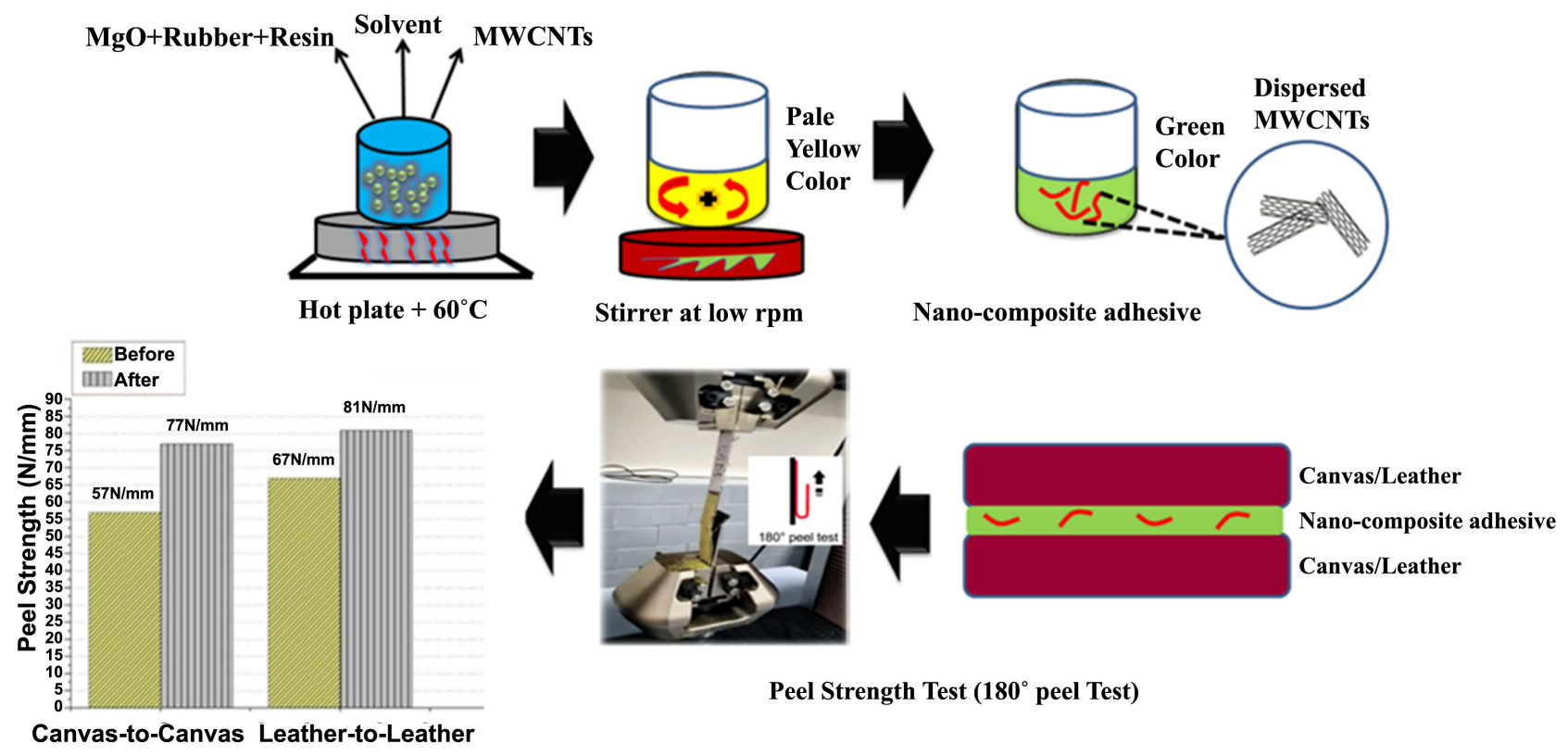

Figure 1. Schematic diagram of preparation of nanocomposite adhesive.

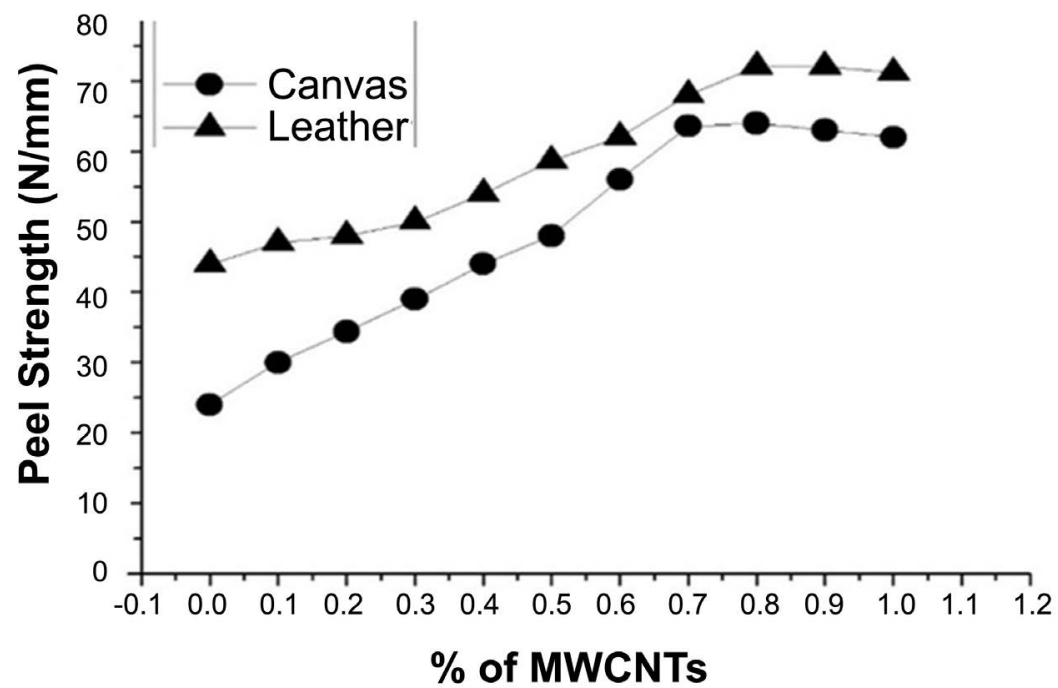

Figure 2. Effect of MWCNTs concentration on peel strength of the Nano composite adhesive.

In Figure 2, a decreasing trend in peel strength after a maximum value, was presumably due to diminution in cohesive forces between adhesive and substrate; it may also be an effect of poor wetting [6]. Another possible reason for the decrease in peel strength could be self-agglomeration of CNTs at higher contents [39].

Figure 3 displays a comparison of the amount of improvement in peel strengths of the unreinforced and reinforced adhesive, indicating a significant enhancement in peel strength on canvas-to-canvas and leather-to-leather substrates. In canvas-to-canvas substrate, peel strength improved up to $35 \%$ while on leather-to-leather substrate the rise was $21 \%$, under optimized conditions. 


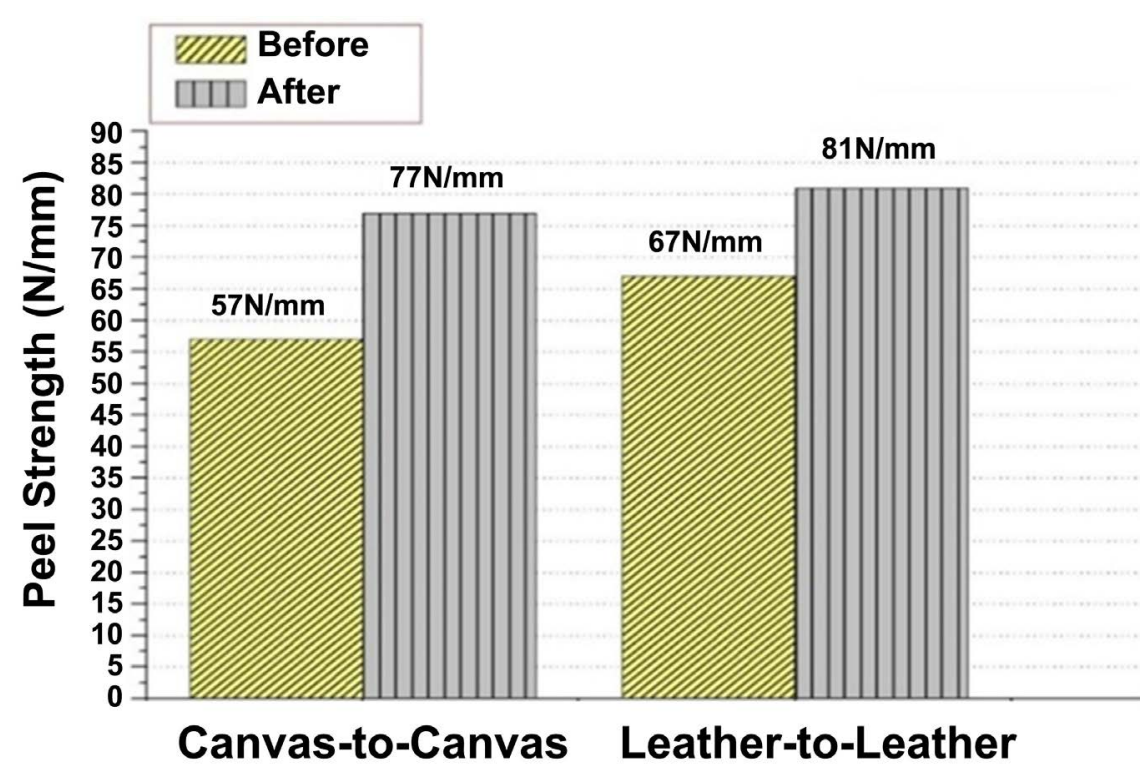

Figure 3. Improvement in peel strength by adding MWCNTs.

The graph demonstrates that the presence of MWCNTs significantly increased the bonding capability of the adhesive. Presumably, the nanotubes caused reinforcement within the adhesive by either possible crack bridging or by crack deflection mechanism which did not allow the crack to propagate at lower loading condition [39].

The (PA-30) unreinforced adhesive formulation showed satisfactory performance in normal environmental conditions; however, it exhibited degradation issues when exposed to humidity, temperature, chemicals, seawater and mechanical loading during service.

The role of MWCNTs was of significant consideration to overcome these ageing conditions, by increasing adhesive stiffness, thermal stability and fracture durability [9]. The reinforced Nano-adhesive (PA-N11) was formulated using MWCNTs to overcome these conditions. Due to the presence of MWCNTs, the adhesive performance was significantly higher in relatively aggressive environments. The bond strength, thermal stability and liquid barrier properties were improved due to incorporation of highly dispersed MWCNTs [40].

The shelf life of the adhesive was estimated by studying ageing under ambient environment. Peel strengths of the unreinforced and reinforced adhesives were determined after shelving at ambient condition for up to 4 months. The data were also compared with commercially available adhesives (Elephant ${ }^{\circledR}$, Dolphin $^{\circledR}$, Samad ultra ${ }^{\circledR}$, Camel $^{\circledR}$ ) of the same category, under similar conditions. Figure 4 and Figure 5 show a graphical comparison of the effect of ageing on peel strengths, tested on canvas-to-canvas and leather-to-leather substrates, respectively.

Table 3 shows the peel strengths of unreinforced and reinforced nanocomposite adhesives, and commercially available adhesives of the same category. PA-30 and commercial adhesives lost their adhesion strength to a mentionable value; 


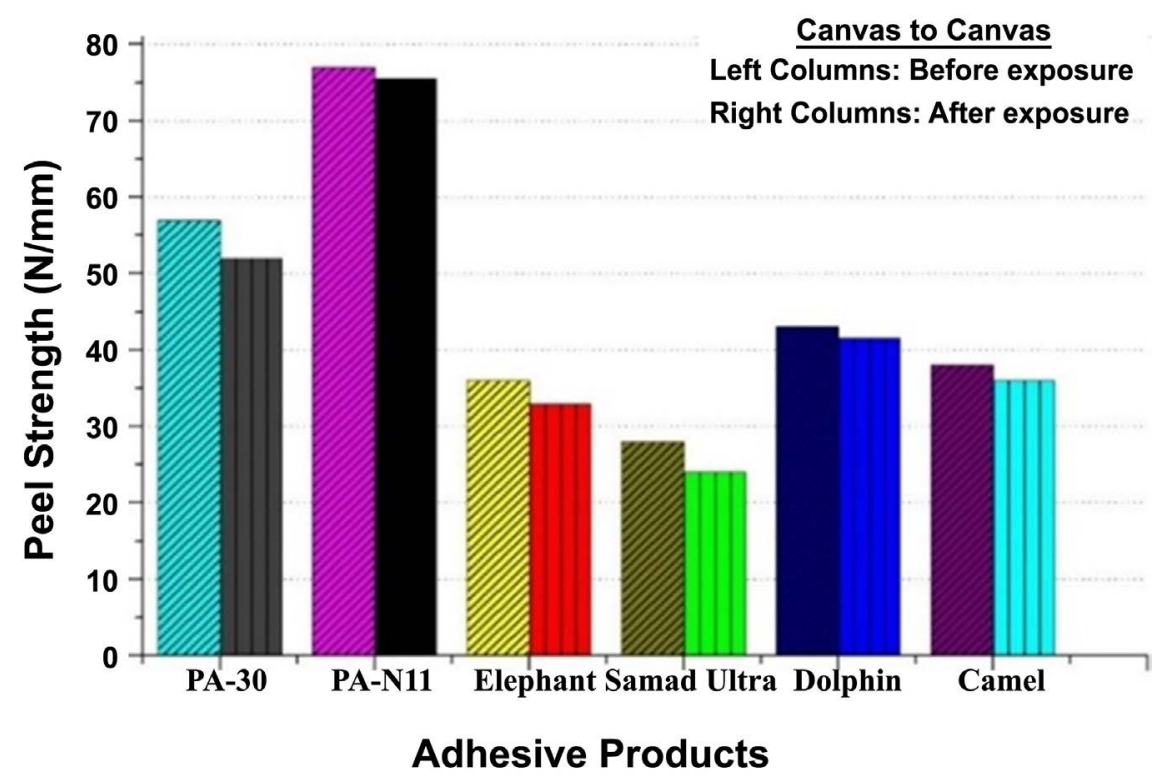

Figure 4. Effect of ageing on peel strengths for various adhesives under the ambient condition on canvas substrate (except PA-30 and PA-N11, all are commercial adhesives of the same category acquired from the local market, indicated by their brand names).

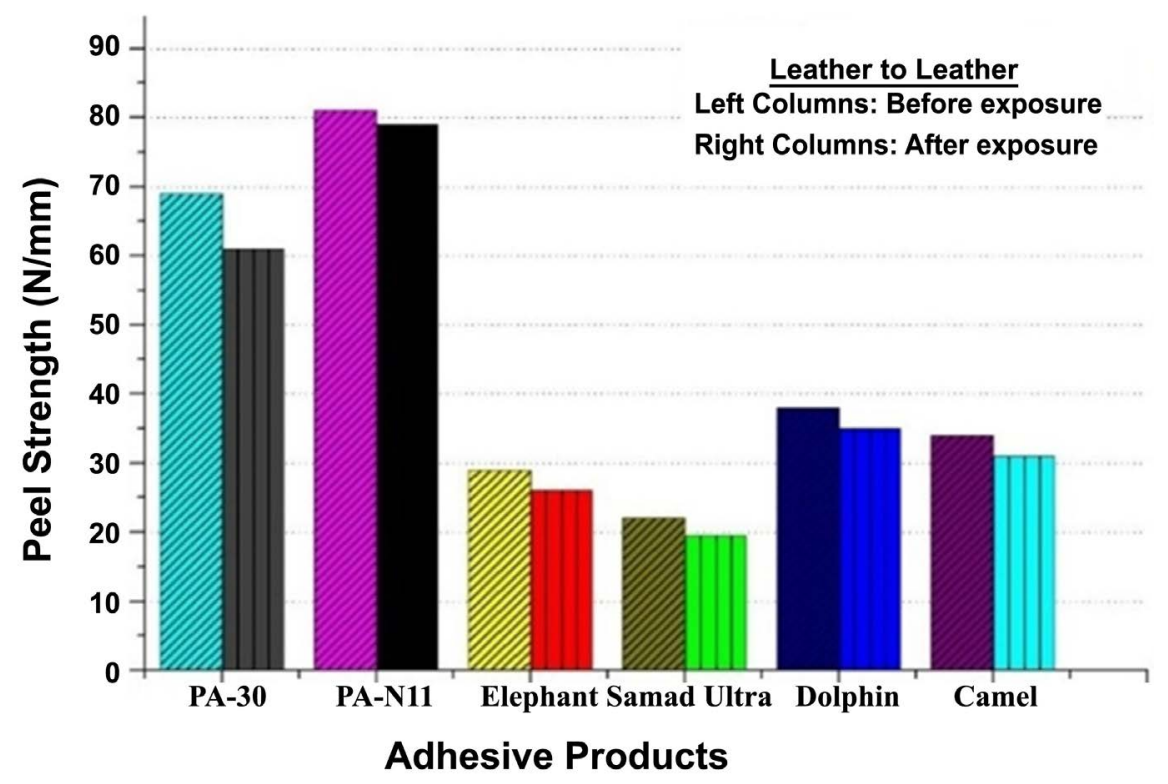

Figure 5. Aging under ambient environment leather substrate.

however, PA-N11 (nanocomposite adhesive) displayed significantly higher performance; the mechanical properties were enhanced with a minimum decrease in peel strength after ageing.

Table 4 shows peel strengths data of various adhesives after the bonds were exposed to of $100^{\circ} \mathrm{C}$. It is believed that the network of crosslinked phenolic resin present in adhesives is usually affected by high temperature. Thermal stability of PA-N11 was enhanced due to the presence of nanotubes which helped to resist high-temperature environment [9]. The flexibility of the adhesive system was 
Table 3. Characteristics of various adhesives under the ambient condition for four month.

\begin{tabular}{ccc}
\hline Adhesive & \multicolumn{1}{c}{ Canvas-to-Canvas } & Leather-to-Leather \\
\hline---- & \% Fall in peel strength & \% Fall in peel strength \\
\hline PA-30 & 8.77 & 11.59 \\
PA-N11 & & 2.47 \\
Elephant $^{\circledR}$ & 1.95 & 10.34 \\
Samad ultra $^{\circledR}$ & 14.29 & 11.36 \\
Dolphin $^{\circledR}$ & 3.26 & 7.89 \\
Camel $^{\circledR}$ & 5.26 & 8.82 \\
\hline
\end{tabular}

${ }^{*}$ Addition of $1 \%$ MWCNTs with adhesive.

Table 4. Characteristics of various adhesives under ageing at $100^{\circ} \mathrm{C}$ for 24 hours.

\begin{tabular}{ccc}
\hline Adhesive & \multicolumn{1}{c}{ Canvas-to-Canvas } & Leather-to-Leather \\
\hline---- & \% Fall in peel strength & \% Fall in peel strength \\
\hline PA-30 & 5.26 & 8.7 \\
PA-N11 & & 4.94 \\
Elephant $^{\circledR}$ & 6.62 & 17.24 \\
Samad ultra $^{\circledR}$ & 13.88 & 22.73 \\
Dolphin $^{\circledR}$ & 23.21 & 13.89 \\
Camel $^{\circledR}$ & 8.37 & 11.76 \\
\hline
\end{tabular}

*Addition of $1 \%$ MWCNTs with adhesive.

essential to operate at high-temperature environment. PA-N11 had better flexibility at high-temperature environment. PA-N11 had a minimal amount of MWCNTs, which provided a better crosslinking network to surfaces of the substrates [40]. Mismatch of properties leads to failure of adhesive bond strength even at low loads and temperature. PA-N11 showed excellent thermal stability in ageing conditions owing to the existence of the MWCNTs crosslinking network.

It is generally known that an adhesive joint is deteriorated when exposed to saltwater since the ability for the diffusion of water increases by the ingress of $\mathrm{Cl}-$ and $\mathrm{Na}+$ in the adhesive joints, resulting in poor durability of the joint [41] [42]. The various adhesive joints were exposed to 3.5\% saltwater at ambient temperature for 24 hours, and the peel strengths were determined. The testing was repeated after every month for for a duration of three months to validate the performance of the adhesives after prolonged shelving. The data is displayed in Figure 6 and Figure 7. Reinforced adhesive showed better resistance compared with unreinforced adhesives including commercial counterparts. The resistance against the corrosive nature of the solution was due to the crosslinking network of MWCNTs in the adhesive. Table 5 summarizes fall in peel strengths as a result of immersion saltwater at ambient temperature for 24 hours. 
Table 5. Characteristics of adhesives under ageing in 3.5\% saltwater for 24 hours.

\begin{tabular}{ccccccc}
\hline Adhesive & \multicolumn{3}{c}{ Canvas-to-Canvas } & \multicolumn{3}{c}{ Leather-to-Leather } \\
\hline---- & \multicolumn{2}{c}{ \% Fall in peel strength } & \multicolumn{2}{c}{ \% Fall in peel strength } \\
\hline PA-30 & 4.39 & 9.30 & 15.79 & 10.14 & 14.35 & 18.12 \\
PA-N11 & 3.9 & 6.49 & 9.74 & 2.47 & 3.95 & 6.79 \\
Elephant & 8.33 & 19.44 & 30.55 & 10.34 & 24.14 & 44.83 \\
Samad ultra & 14.29 & 25 & 36.84 & 8.38 & 19.37 & 36.11 \\
Dolphin & 10.23 & 20.93 & 30.23 & 10.34 & 24.13 & 44.82 \\
Camel & 10.53 & 23.68 & 38.84 & 11.76 & 20.59 & 38.23 \\
\hline
\end{tabular}

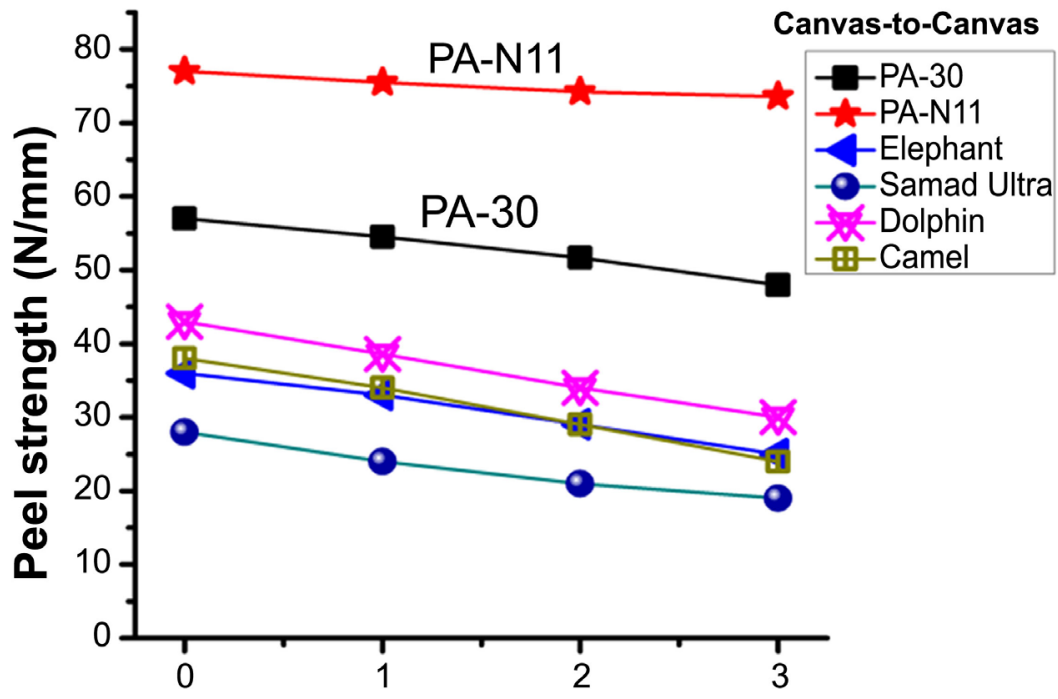

Months

Figure 6. Three months ageing comparison in a brine solution (canvas substrate).

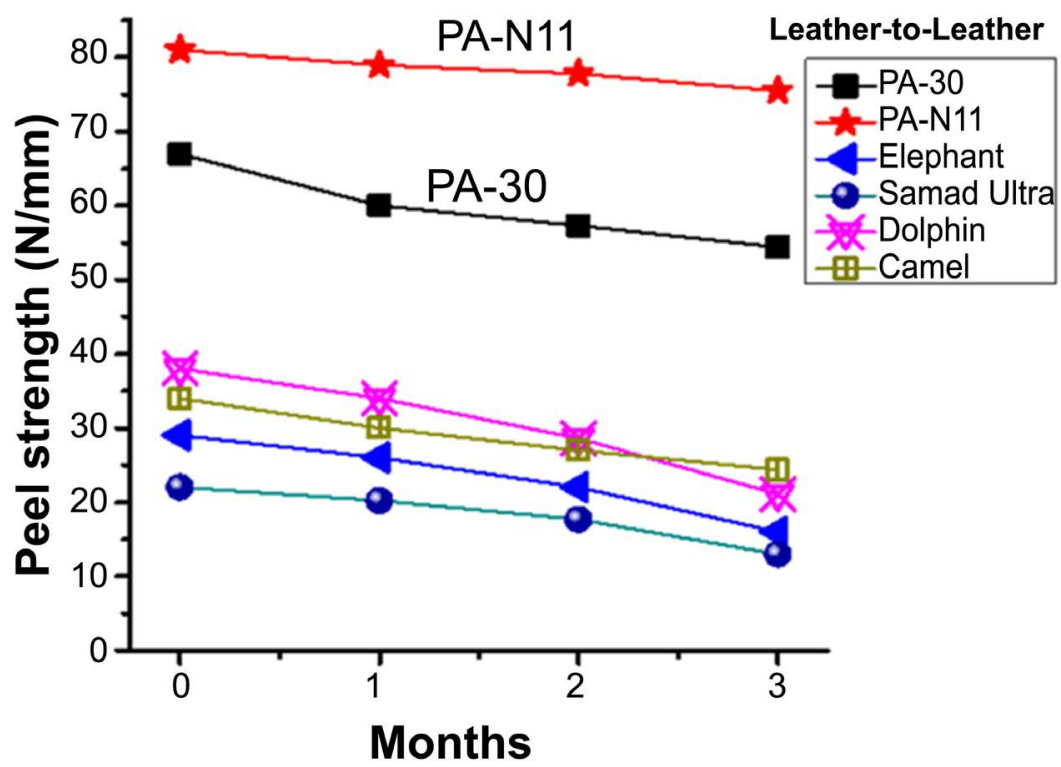

Figure 7. Three months ageing comparison in a brine solution (leather substrate). 


\section{Conclusion}

Incorporation of MWCNTs in the solvent-based adhesive successfully improves the bond strength of adhesive joint on flexible substrates. The formulations of PA-30 (unreinforced adhesive) exhibited improvement in $180^{\circ}$ peel strengths on canvas and leather substrates, up to $57 \mathrm{~N} / \mathrm{mm}$ and $67 \mathrm{~N} / \mathrm{mm}$, respectively. The formulation of PA-N11 (1\% MWCNTs), demonstrated an enhancement in peel strength up to $77 \mathrm{~N} / \mathrm{mm}$ on canvas and $81 \mathrm{~N} / \mathrm{mm}$ on leather substrates respectively. The improvement in peel strength was $35 \%$ on canvas and $21 \%$ on leather substrates as compared to unreinforced adhesive. The optimized unreinforced adhesive displayed a $25 \%$ - 50\% increase in peel strength compared with commercial adhesives used for investigation. The optimized reinforced adhesive showed $46 \%$ - 64\% increase in peel strength compared with commercial adhesives investigated. Fall in peel strength of unreinforced adhesive after 4-month shelving at the ambient environment, was $8 \%-10 \%$, whereas the reinforced adhesives showed a decrease of $2 \%-3 \%$. Fall in peel strength of unreinforced adhesive after 24 hours' immersion in $3.5 \%$ sodium chloride solution was $12 \%$ $17 \%$, whereas the reinforced adhesives showed a decrease of $4 \%-6 \%$.

\section{Acknowledgements}

The authors acknowledge the Pakistan Science Foundation financial grant to carry out this research work under Grant No.089, April 2019.

\section{Conflicts of Interest}

The authors declare no conflicts of interest regarding the publication of this paper.

\section{References}

[1] Zhang, K., Shen, H.F., Zhang, X.Y., Lan, R.H. and Chen, H.Q. (2009) Preparation and Properties of a Waterborne Contact Adhesive Based on Polychloroprene Latex and Styrene-Acrylate Emulsion Blend. Journal of Adhesion Science and Technolo$g y, 23,163-175$. https://doi.org/10.1163/156856108X344658

[2] Brown, H.R. (2000) Adhesion between Polymers and Other Substances-A Review of Bonding Mechanisms, Systems and Testing. Materials Forum, 24, 49-58. https://www.azom.com/article.aspx?ArticleID=2089

[3] Kozuh, Z., Kralj, S. and Cvirn, Z. (1997) Advantages and Application Possibilities of Adhesive Bonding. Promet-Traffic \& Transportation, 9, 33-40.

[4] Barry, C.P., Morose, G.J., Begin, K., Atwater, M. and Hansen, C.J. (2017) The Identification and Screening of Lower Toxicity Solvents for Contact Adhesives. International Journal of Adhesion and Adhesives, 78, 174-181. https://doi.org/10.1016/j.ijadhadh.2017.06.022

[5] Baldan, A. (2004) Adhesively-Bonded Joints and Repairs in Metallic Alloys, Polymers and Composite Materials: Adhesives, Adhesion Theories and Surface Pretreatment. Journal of Materials Science, 39, 1-49. https://doi.org/10.1023/B:JMSC.0000007726.58758.e4 
[6] Marshall, S.J., Bayne, S.C., Baier, R., Tomsia, A.P. and Marshall, G.W. (2010) A Review of Adhesion Science. Dental Materials, 26, e11-e16. https://doi.org/10.1016/j.dental.2009.11.157

[7] Gierenz, G. and Karmann, W. (2001) Adhesives and Adhesive Tapes. Wiley-VCHGMBH, Hoboken. https://doi.org/10.1002/9783527612802

[8] Ebnesajjad, S. (2008) Adhesive Technology Handbook. 2nd Edition, William Andrew, Norwich, 7.

[9] Martin-Martinez, J.M. (2002) Rubber Base Adhesives. Adhesion Science and Engineering, 2, 573-675. https://doi.org/10.1016/B978-044451140-9/50013-5

[10] Zhang, L., Hu, J. and Athanasiou, K.A. (2009) The Role of Tissue Engineering in Articular Cartilage Repair and Regeneration. Critical Reviews in Biomedical Engineering, 37, 1-57. https://doi.org/10.1615/CritRevBiomedEng.v37.i1-2.10

[11] Paiva, R.M.M., Marques, E.A.S., da Silva, F.M.L. and Aran-Ais, F. (2015) Adhesives in the Footwear Industry. Proceedings of Institution of Mechanical Engineers, Part L: Journal of Materials Design and Applications, 230, 357-374. https://doi.org/10.1177/1464420715602441

[12] Shull, K.R. (2002) Contact Mechanics and the Adhesion of Soft Solids. Materials Science and Engineering: R: Reports, 36, 1-45.

https://doi.org/10.1016/S0927-796X(01)00039-0

[13] Good, R.J. (1992) Contact Angle, Wetting, and Adhesion: A Critical Review. Journal of Adhesion Science and Technology, 6, 1269-1302. https://doi.org/10.1163/156856192X00629

[14] Tong, Q.K., Markley, D.L., Frederickson, G., Kuder, R. and Lu, D. (1999) Conductive Adhesives with Stable Contact Resistance and Superior Impact Performance. 1999 Proceedings 49th Electronic Components and Technology Conference (Cat. No. 99CH36299), San Diego, 347-352.

[15] Hartshorn, S.R. (1986) Structural Adhesives: Chemistry and Technology. Plenum Press, New York. https://doi.org/10.1007/978-1-4684-7781-8

[16] Archer, B. (1998) Water Based Contact Adhesives-New Developments. International Journal of Adhesion and Adhesives, 18, 15-18. https://doi.org/10.1016/S0143-7496(97)00061-4

[17] Kim, T.H. (2014) Bonding. In: Laperrière, L. and Reinhart, G., Eds., CIRP Encyclopedia of Production Engineering, The International Academy for Production Engineering, Springer, Berlin, Heidelberg, 1-39.

[18] Pizzi, A. and Mittal, K.L. (2017) Handbook of Adhesive Technology. 3rd Edition, CRC Press, Boca Raton.

[19] Ungureanu, D., Taranu, N., Lupasteanu, V., Rosu, A. and Mihai, P. (2016) The Adhesion Theories Applied to Adhesively Bonded Joints of Fiber Reinforced Polymer Composite Elements. Bulletin of the Polytechnic Institute of Jassy, Constructions, Architecture Section, 62, 37.

[20] Morton, M. (1999) Rubber Technology. Springer, Berlin. https://doi.org/10.1007/978-94-017-2925-3

[21] Derjaguin, B.V., Churaev, N.V. and Muller, V.M. (1987) Forces near Interfaces. Springer, Berlin, 1-23. https://doi.org/10.1007/978-1-4757-6639-4_1

[22] Persson, B.N.J. and Scaraggi, M. (2014) Theory of Adhesion: Role of Surface Roughness. Journal of Chemical Physics, 141, Article ID: 124701. https://doi.org/10.1063/1.4895789

[23] Lipatov, Y.S., Jennings, B.R., Basedow, A.M. and Ebert, K. (1977) Physical Chemi- 
stry. Springer, Berlin.

[24] Yang, S., Gu, L. and Gibson, R. (2001) Nondestructive Detection of Weak Joints in Adhesively Bonded Composite Structures. Composite Structures, 51, 63-71. https://doi.org/10.1016/S0263-8223(00)00125-2

[25] Carothers, W.H., Williams, I., Collins, A.M. and James, E.K. (1931) Acetylene Polymers and Their Derivatives. II. A New Synthetic Rubber: Chloroprene and its Polymers. Journal of the American Chemical Society, 53, 4203-4225. https://doi.org/10.1021/ja01362a042

[26] Irving, S. (1990) Handbook of Adhesives. Van Nostrand Reinhold, New York, NY, Springer, US, Vol. 104, No. 800. https://doi.org/10.1007/978-1-4613-0671-9

[27] Pocius, A.V. (1986) Fundamentals of Structural Adhesive Bonding. In: Structural Adhesives, Springer US, Boston, 23-68. https://doi.org/10.1007/978-1-4684-7781-8_2

[28] Wypych, G. (2014) Solvent Use in Various Industries: Asphalt Compounding. In: Handbook of Solvents, Second Edition, Elsevier, Amsterdam, Vol. 2, 13-14.

[29] Pizzi, A. and Mittal, K.L. (2019) Wood Adhesives. Taylor \& Francis, Abingdon-on-Thames. https://doi.org/10.1201/9780203733721

[30] Wingfield, J.R.J. (1993) Treatment of Composite Surfaces for Adhesive Bonding. International Journal of Adhesion and Adhesives, 13, 151-156. https://doi.org/10.1016/0143-7496(93)90036-9

[31] Noeske, M., Degenhardt, J., Strudthoff, S. and Lommatzsch, U. (2004) Plasma Jet Treatment of Five Polymers at Atmospheric Pressure: Surface Modifications and the Relevance for Adhesion. International Journal of Adhesion and Adhesives, 24, 171-177. https://doi.org/10.1016/j.ijadhadh.2003.09.006

[32] Molitor, P., Barron, V. and Young, T. (2001) Surface Treatment of Titanium for Adhesive Bonding to Polymer Composites: A Review. International Journal of Adhesion and Adhesives, 21, 129-136. https://doi.org/10.1016/S0143-7496(00)00044-0

[33] Rodrigues, S.B., Petzhold, C.L., Gamba, D., Leitune, V.C.B. and Collares, F.M. (2018) Acrylamides and Methacrylamides as Alternative Monomers for Dental Adhesives. Dental Materials, 34, 1634-1644. https://doi.org/10.1016/j.dental.2018.08.296

[34] Bouvet, G., Cohendoz, S., Feaugas, X., Touzain, S. and Mallarino, S. (2017) Microstructural Reorganization in Model Epoxy Network during Cyclic Hygrothermal Ageing. Polymer, 122, 1-11. https://doi.org/10.1016/j.polymer.2017.06.032

[35] Krzeminska, S. and Rzymski, W.M. (2013) Thermodynamic Affinity of Elastomer-Solvent System and Barrier Properties of Elastomer Materials in Adhesive Systems. Acta Physica Polonica A, 124, 146-150. https://doi.org/10.12693/APhysPolA.124.146

[36] Font, R., Sabater, M.C. and Martínez, M.A. (2001) Reduction of Solvent Content in Toluene-Neoprene Adhesives and in Acetone-Polyurethane Adhesives. Journal of Adhesion Science and Technology, 15, 1677-1693. https://doi.org/10.1163/15685610152715719

[37] Wan, Y., Gong, L., Tang, L., Wu, L. and Jiang, J. (2014) Composites: Part A Mechanical Properties of Epoxy Composites Filled with Silane-Functionalized Graphene Oxide. International Journal of Polymer Science, 64, 79-89.

https://doi.org/10.1016/j.compositesa.2014.04.023

[38] Razavi, S.M.J., Ayatollahi, M.R., Majidi, H.R. and Berto, F. (2018) A Strain-Based Criterion for Failure Load Prediction of Steel/CFRP Double Strap Joints. Composite 
Structures, 206, 116-123. https://doi.org/10.1016/j.compstruct.2018.08.046

[39] Zhai, L.L., Ling, G.P.Ã. and Wang, Y.W. (2007) Effect of $\mathrm{Nano}_{2} \mathrm{Al}_{2} \mathrm{O}_{3}$ on Adhesion Strength of Epoxy Adhesive and Steel. International Journal of Adhesion and Adhesives, 28, 23-28. https://doi.org/10.1016/j.ijadhadh.2007.03.005

[40] Robaidi, A.A., Anagreh, N. and Massadeh, S. (2011) The Effect of Different Surface Pretreatment Methods on Nano-Adhesive Application in High Strength Steel and Aluminum Bonding. Journal of Adhesion Science and Technology, 64, 79-89.

[41] Knox, E.M. and Cowling, M.J. (2000) A Rapid Durability Test Method for Adhesives. International Journal of Adhesion and Adhesives, 20, 201-208. https://doi.org/10.1016/S0143-7496(99)00045-7

[42] Wang, C., Huang, Y.D., Xv, H.Y. and Liu, W.B. (2004) The Durability of Adhesive/Carbon-Carbon Composites Joints in Salt Water. International Journal of Adhesion and Adhesives, 24, 471-477. https://doi.org/10.1016/j.ijadhadh.2004.01.001 